FROM: Sands KE, Bates DW, Lanken PN, et al. Epidemiology of sepsis syndrome in eight academic medical centers. Academic Medical Center Consortium Sepsis Project Working Group. JAMA 1997;278:234-240.

\section{PCR-A Cost-Effective Alternative for VRE Screening}

Surveillance cultures for vancomycin-resistant enterococci (VRE) are time-consuming and expensive for the laboratory to perform. In an effort to reduce the time of routine assays, investigators from the CDC's Hospital Infections Program conducted an extensive study on the use of polymerase chain reaction (PCR) as an alternative method of detecting and identifying VRE directly in fecal samples.

PCR primers, directed to $\operatorname{van} \mathrm{A}, \operatorname{van} B, \operatorname{van} C 1, \operatorname{van} \mathrm{C} 2$, and enterococcal ligase genes, were used to detect and identify VRE in fecal material obtained by rectal or perirectal swabbing. Although PCR-inhibitory substances were present in DNA prepared directly from the swabs, the inhibitory substances could be reduced by processing the nucleic acid with two commercially available DNA preparation columns. Cultures were grown on several selective agar media, before and after broth enrichment, from fecal material from 333 swabs. DNA was extracted from the fecal material and was analyzed by PCR. By using all four primer sets, only $59(67.8 \%)$ of the samples were positive for $\operatorname{vanA}$. However, after retesting the negative samples with only the vanA primer set, $77(88.5 \%)$ of 87 specimens that were culture-positive for Enterococcus faecium containing vanA were positive by PCR One specimen was PCR-positive for the vanA gene, but culture-negative for enterococci. The specificity of the vanA assay was $99.6 \%$. PCR analysis of enrichment broth samples with all four primers sets after 15 to 18 hours of incubation detected $74(85.1 \%)$ of the 87 culture-positive specimens. The specificity of the $\operatorname{van} \mathrm{A}$ assay after the enrichment step was $100 \%$. No vanB -containing enterococci were recovered by culture.

Because 16 samples can be tested by PCR in 4 hours (including electrophoresis), identification of VRE is possible within 8 hours of specimen submission at a cost of approximately $\$ 10.12$ per assay. The authors concluded that PCR may be a cost-effective alternative to culture for surveillance of VRE in some hospitals.

FROM: Satake S, Clark N, Rimland D, Nolte FS,
Tenover FC. Detection of vancomycin-resistant enterococci in fecal samples by PCR. J Clin Microbiol 1997;35:2325-2330

\section{National Guidelines Control Antibiotic Use -- Finland}

In the early 1990 s, there was an increase in erythromycin resistance among group A streptococci in Finland. In response, policies regarding outpatient antibiotic therapy were changed, and nationwide recommendations were issued that called for reductions in the use of macrolide antibiotics for respiratory and skin infections in outpatients. Investigators at the Antimicrobial Research Laboratory, National Public Health Institute, Turku, Finland, studied the effect of this national policy on the pattern of erythromycin resistance throughout Finland. Between 1991 and 1996, a total of 39,247 group A streptococcal isolates from throat swabs ( $82 \%$ of the isolates) and pus samples (18\%) and 290 isolates from blood cultures were studied in regional microbiology laboratories. The susceptibility of the isolates to erythromycin was tested by the disk-diffusion or the screening-plate method. Study results showed that consumption of macrolide antibiotics decreased from 2.40 defined daily doses, per 1,000 inhabitants per day in 1991 to 1.38 in $1992(P<.007)$ and remained near the lower level during the study period. The change in consumption was followed by a steady decrease in the frequency of erythromycin resistance among group A streptococcal isolates from throat swabs and pus samples, from 16.5\% in 1992 to $8.6 \%$ in 1996 (odds ratio for 1996 as compared with 1992, 0.5; 95\% confidence interval, 0.4-0.5). The authors concluded that, in Finland, after nationwide reductions in the use of macrolide antibiotics for outpatient therapy, there was a significant decline in the frequency of erythromycin resistance among group A strep tococci isolated from throat swabs and pus samples.

FROM: Seppala H, Klaukka T, Vuopio-Varkila J, et al. The effect of changes in the consumption of macrolide antibiotics on erythromycin resistance in group A streptococci in Finland. Finnish Study Group for Antimicrobial Resistance. N Engl J Med 1997;337:441-446.

Additional news item in this issue: Outbreak of Mycoplasma Pneumonia, p 782. 